\title{
Compreensão textual de artigos originais de pesquisa por graduandos em química
}

\author{
Text comprehension of research articles by undergraduate chemistry \\ students
}

\section{Flávia Gabriele Sacchi ' ; Salete Linhares Queiroz "}

\section{RESUMO}

A leitura e compreensão de artigos originais de pesquisa (AOP) por graduandos em química proporciona uma maior capacidade na elaboração de críticas e no estabelecimento de relações entre conteúdos científicos. Mesmo se constituindo em habilidade tão relevante, pesquisas acerca da temática são escassas, principalmente no contexto nacional. Nessa perspectiva, este trabalho tem como objetivo principal a investigação da compreensão textual de AOP sobre o assunto biocombustível, extraído da revista Química Nova, por graduandos da área, no contexto de uma disciplina de comunicação científica. Para tanto, foi analisada, inicialmente, a retextualização realizada por um grupo de alunos de um AOP para exposição oral correspondente e, em seguida, foram estabelecidas relações entre tais operações e a compressão textual. A análise se deu a partir de estudos sobre operações de retextualização e compreensão textual, na perspectiva proposta por Marcuschi. Os resultados apontaram que a elaboração dos slides componentes da exposição oral ocorreu sem prejuízos ao propósito comunicativo estabelecido pelos autores do AOP, sugerindo a sua compreensão por parte dos graduandos.

Palavras-chave: Compreensão textual; Artigo original de pesquisa; Química 
ABSTRACT

Reading and comprehension of research articles (RA) by undergraduate chemistry students provides a greater ability to develop criticism and establish links between scientific contents. Even being such a relevant skill, research on the subject is scarce, especially in the Brazilian context. From this perspective, this paper aims to investigate the text comprehension of RA about the topic of biofuel, extracted from the "Química Nova" journal, by undergraduates from the area, in the context of a scientific communication discipline. Therefore, we initially analyzed the retextualization carried out by a group of students from RA for corresponding oral presentation, and then established links between retextualization operations and text comprehension. The analysis was based on studies on retextualization operations and text comprehension, from the perspective proposed by Marcuschi. The results indicated that the development of the oral presentation component slides took place without impairing the communicative purpose established by the RA authors, suggesting the undergraduates understood it.

Keywords: Text comprehension; Research articles; Chemistry

\section{INTRODUÇÃO}

De acordo com Kleiman (2008), o processo de compreensão textual é o resultado da interação entre o conhecimento prévio do leitor e o texto. Marcuschi, por sua vez, aponta que (2008, p. 228):

Trabalhar a compreensão hoje em dia é bastante complexo. Muitos são os estudos sobre o tema e igualmente variadas são as posições teóricas. Não há uma teoria hegemônica ou que seja a mais correta e definitiva. Ler é um ato de produção e apropriação de sentido que nunca é definitivo e completo. Aqui vamos defender a posição de que ler não é um ato de simples extração de conteúdo ou identificação de sentidos. Mas não se pode dizer que ler seja apenas uma experiência individual sobre o texto, oral ou escrito. Compreender o outro é uma aventura, e nesse terreno não há garantias absolutas ou completas. Antes de qualquer coisa, deve-se ter clareza quanto ao fato de que nossa compreensão está ligada a esquemas cognitivos internalizados, mas não 
individuais e únicos. Assim, a percepção é, em boa medida, guiada e ativada pelo nosso sistema sociocultural internalizado ao longo da vida. Nossas experiências, por sua vez, são uma construção com base em sensações organizadas e não um fruto puro e simples de sensações primárias.

No que se refere ao ensino superior, é esperado que os graduandos sejam capazes de ler e compreender um texto, a partir da articulação, fluência e análise crítica das informações dispostas pelo autor (CUNHA; SANTOS, 2006). Tal afirmação está alinhada com as Diretrizes Curriculares Nacionais para os Cursos de Química (BRASIL, 2001), que colocam a leitura, a compreensão e a interpretação de artigos científicos dentre as habilidades desejáveis dos graduandos da área. Em contraponto, trabalhos acerca da leitura e compreensão textual de artigos científicos no ensino superior de química são escassos, mesmo diante da sua importância para a formação profissional. De fato, em levantamento bibliográfico realizado por Francisco Júnior (2010) sobre estratégias de leitura na educação em química, foram identificados treze trabalhos, dentre os quais apenas três são voltados a artigos dessa natureza (MASSI et al., 2009; SANTOS; SÁ; QUEIROZ, 2006; SANTOS; QUEIROZ, 2007).

Os autores dos trabalhos intitulados "Uso de artigos científicos em uma disciplina de físico-química" (SANTOS; SÁ; QUEIROZ, 2006) e "Leitura e interpretação de artigos científicos por alunos de graduação em química" (SANTOS; QUEIROZ, 2007) descreveram a aplicação propriamente dita de artigos científicos em disciplinas de graduação em química. Enquanto no primeiro foi solicitada aos estudantes a leitura e posterior redação de resumos referentes aos assuntos tratados nos artigos lidos, no segundo foi solicitada a elaboração de apresentações orais e painéis. Com relação ao primeiro trabalho, foram também coletadas as percepções dos envolvidos sobre a atividade realizada, que mostraram o papel creditado por eles à utilização do artigo científico como promotor da aprendizagem de conceitos de química, do aprimoramento da capacidade de expressão em linguagem escrita e de localização de referências bibliográficas.

Em contraponto, no trabalho intitulado "Artigos científicos como recurso didático no ensino superior de química", Massi et al. (2009) realizaram uma revisão 
sobre o assunto em pauta, tendo sido localizados trinta artigos. A análise dos mesmos revelou, dentre outros aspectos, os principais objetivos para o seu uso: ensino e aprendizagem de conteúdos específicos de disciplinas dos cursos de graduação; aperfeiçoamento de habilidades de comunicação orais e escritas em linguagem científica; familiarização com a literatura primária (localização, reconhecimento de características, leitura crítica e compreensão); entendimento sobre o processo de construção do conhecimento científico; familiarização com as atividades de pesquisa científica.

Tendo em vista as potencialidades do uso de artigos científicos em cursos de graduação em química e a escassez de trabalhos a respeito, especialmente no cenário nacional, este trabalho tem como objetivo principal a investigação da compreensão textual de artigos científicos, doravante denominados artigos originais de pesquisa (AOP), por parte dos graduandos, no contexto de uma disciplina de comunicação científica. Para tanto, foi realizada a análise da retextualização dos AOP para exposições orais (EO) e o estabelecimento de relações entre tais operações e a compressão textual.

Nessa perspectiva, a pesquisa aqui apresentada pretende contribuir para a ampliação de estudos que fornecem subsídios teórico-metodológicos que possam redimensionar as atividades de ensino-aprendizagem desenvolvidas em cursos de graduação em química, com o objetivo de fomentar habilidades relacionadas à leitura e compreensão de AOP.

\section{METODOLOGIA}

Os dados da presente pesquisa foram coletados na disciplina Comunicação e Expressão em Linguagem Científica II, oferecida no segundo semestre do Curso de Bacharelado em Química do Instituto de Química de São Carlos da Universidade de São Paulo. A turma era constituída por trinta alunos, que realizaram a maioria das suas atividades divididos em grupos. 
Os AOP utilizados foram selecionados da revista Química Nova (Quadro 1).

Quadro 1 - AOP selecionados para leitura dos graduandos em química

\begin{tabular}{|l|l|}
\hline $\mathbf{N}^{\circ}$ & Título do AOP e localização no acervo da revista Química Nova \\
\hline 1 & $\begin{array}{l}\text { Caracterização físico-química de resíduos oleosos do saneamento e dos óleos e graxas } \\
\text { extraídos visando a conversão em biocombustíveis. Química Nova, v.37, n.4, p. 597-602, } \\
\text { 2014. }\end{array}$ \\
\hline 2 & $\begin{array}{l}\text { Transesterificação de óleos vegetais: caracterização por cromatografia em camada delgada e } \\
\text { densidade. Química Nova, v.30, n.8, p. 2016-2019, 2007. }\end{array}$ \\
\hline 3 & $\begin{array}{l}\text { Caracterização de resíduo sólido formado em biodiesel de sebo bovino. Química Nova. v.35, } \\
\text { n.10, p.1901-1906, 2012. }\end{array}$ \\
\hline 4 & $\begin{array}{l}\text { Análise comparativa do conteúdo em esteroides livres de diferentes óleos, gorduras e } \\
\text { biodieseis por cromatografia gasosa. Química Nova, v. 38, n. 4, p. 498-505, 2015. }\end{array}$ \\
\hline 5 & $\begin{array}{l}\text { Biodiesel de soja - taxa de conversão em ésteres etílicos, caracterização físico-química e } \\
\text { consumo em gerador de energia. Química Nova, v. 28, n. 1, p. 19-23, 2005. }\end{array}$ \\
\hline 6 & $\begin{array}{l}\text { Tratamento do efluente do biodiesel utilizando a eletrocoagulação/flotação: investigação dos } \\
\text { parâmetros operacionais. Química Nova, v. 35, n. 2, p. 235-240, 2012. }\end{array}$ \\
\hline 7 & \begin{tabular}{l} 
Utilização de argilas para a purificação de biodiesel. Química Nova, v. 34, n. 1, p. 91-95, 2011. \\
\hline
\end{tabular}
\end{tabular}

Fonte: Os autores

A escolha dos AOP, que tratam da temática biodiesel, se justifica por estarem escritos em língua portuguesa, não serem muito longos (em média seis páginas) e abordarem assuntos que não exigem o conhecimento de técnicas analíticas complexas. O atendimento de tais critérios é relevante devido ao fato de os alunos cursarem o segundo semestre do Curso de Bacharelado em Química e não possuírem ainda conhecimentos de determinados conteúdos de química. A desconsideração desse contexto poderia comprometer o entendimento sobre o assunto em pauta. Trabalhos reportados na literatura indicam a viabilidade de aplicação de atividades didáticas com textos da referida revista junto a calouros (MASSI et al., 2009, SANTOS; QUEIROZ, 2007).

Uma Sequência Didática (SD) baseada na retextualização do AOP para a EO foi levada a cabo. A conveniência da sua aplicação se deve ao fato de o principal objetivo da disciplina consistir no aprimoramento das capacidades de escrita, leitura e comunicação oral dos estudantes, e não no ensino de conteúdos de química. 
A SD englobou um conjunto de atividades organizadas com base nos gêneros textuais AOP e EO, conforme mostra a Tabela 1 (DOLZ et al., 2004).

Tabela 1 - Etapas da SD aplicada na disciplina de comunicação científica

\begin{tabular}{cccc}
\hline $\begin{array}{c}\text { Apresentação da } \\
\text { situação }\end{array}$ & Produção inicial & Módulos intermediários & Produção final \\
\hline $\begin{array}{c}\text { Atividades de revisão } \\
\text { sobre as características } \\
\text { do AOP e de instrução } \\
\text { sobre as características } \\
\text { da EO }\end{array}$ & $\begin{array}{c}\text { EO prévia do AOP e } \\
\text { comentários do } \\
\text { docente }\end{array}$ & $\begin{array}{c}\text { Discussão das características } \\
\text { estruturais e retóricas do AOP }\end{array}$ & EO final do AOP \\
\hline
\end{tabular}

Na etapa de apresentação da situação (Tabela 1), os estudantes foram divididos em cinco grupos de cinco com quatro integrantes cada e dois com cinco integrantes cada. Foi entregue um AOP para cada grupo para a realização das atividades de elaboração das EO. Foram ministradas aulas expositivas dialogadas pelo docente responsável, para a revisão das características estruturais do AOP, bem como para as orientações sobre a produção das EO no meio acadêmico. Cabe destacar que os estudantes possuíam embasamento sobre as características estruturais do AOP por terem cursado a disciplina de Comunicação e Expressão em Científica I, pré-requisito à da aplicação da SD.

A etapa de produção inicial consistiu na delimitação da elaboração de uma EO prévia acerca do conteúdo do AOP por parte dos estudantes, de maneira simplificada, com foco na Introdução e Parte Experimental, com duração estimada de dez minutos, utilizando como material de apoio slides elaborados em editores de apresentações, como o PowerPoint ${ }^{\mathrm{TM}}$. O objetivo da EO foi o de introduzir a temática e elucidar as técnicas e procedimentos experimentais envolvidos no AOP estudado, que poderiam ser desconhecidos dos colegas. Assim, o docente responsável pode decidir em quais momentos sua intervenção seria necessária, para auxiliar os estudantes em busca dos objetivos didáticos almejados (DOLZ et al., 2004). 
Os módulos intermediários foram definidos a partir das conclusões extraídas da etapa de produção inicial. Estes estiveram vinculados à realização de atividades que propiciassem o desenvolvimento da habilidade de leitura crítica do AOP. Nessa perspectiva, atividades que fomentassem 0 entendimento não somente das características estruturais, mas também das características retóricas do AOP foram realizadas e demandaram reflexão sobre a construção e os valores que permeiam os trabalhos de natureza científica.

Assim, de acordo com os resultados advindos do acompanhamento do processo de produção inicial, o seguinte procedimento foi adotado: foi realizada a leitura e discussão em grupo do material didático disponibilizado como Material Suplementar do artigo intitulado "A retórica da linguagem científica: das bases teóricas à elaboração de material didático para o ensino superior de química" (OLIVEIRA; QUEIROZ, 2012). Nele constam sete atividades, das quais três foram exploradas pelos alunos e tratavam dos aliados dos textos científicos, da cautela e audácia do autor na redação dos textos científicos e dos tipos de citações nos textos científicos.

A etapa de produção final se deu a partir da elaboração da EO baseada no conteúdo, na íntegra, do AOP (Introdução, Parte Experimental, Resultados e Discussão, Conclusões e Bibliografia), com duração estimada de quinze a vinte minutos, utilizando como material de apoio slides produzidos em editores de apresentações, como o PowerPoint ${ }^{\mathrm{TM}}$. Ao final de cada apresentação os colegas realizaram perguntas sobre a EO e estas foram respondidas pelos integrantes do grupo do apresentador e por ele próprio. Essa produção final foi solicitada com o objetivo de o aluno colocar em prática o que foi aprendido nas atividades anteriores e possibilitar a avaliação do docente acerca da sua evolução em relação à produção inicial (DOLZ et al., 2004).

Considerando as atividades supracitadas, o corpus deste trabalho se constitui na EO final produzida por integrantes de um dos grupos formados na disciplina, no artigo que serviu de texto base para a elaboração da EO e nos slides produzidos como material de apoio à EO. 
A análise dos dados ocorreu em duas etapas. Na primeira etapa foram investigadas as operações de retextualização, empregadas na passagem do AOP para o conteúdo dos slides da EO, na perspectiva de Marcuschi (2010). Para isso, foi necessária a leitura do AOP e a localização de trechos que serviram de base para a retextualização. A segunda etapa consistiu na caracterização dos horizontes de compreensão textual, propostos por Marcuschi (2008), para cada unidade de análise (UA), a partir da identificação de perspectivas que apontam para a predominância de um deles: horizonte máximo, horizonte mínimo, falta de horizonte, horizonte problemático ou horizonte indevido. Essas perspectivas são identificadas com base nas operações de retextualização colocadas em funcionamento.

No entanto, algumas UA podem apresentar mais de um horizonte de compreensão textual e nesses casos, no presente estudo, foi feita a indicação de cada um deles. Em suma, os dados foram organizados em UA, nas quais é possível verificar as operações de retextualização e, assim, associá-las a determinadas perspectivas que, uma vez identificadas, permitem a caracterização do horizonte de compreensão textual. O Quadro 2 exemplifica uma UA, tendo em vista o melhor entendimento do leitor sobre as suas características.

Quadro 2 - Exemplo de UA com indicação das operações de retextualização

2. Devido aos elevados teores de OGRs, a escuma apresenta alto potencial a ser utilizada como matéria-prima na produção de biodiesel.

OGRs como o óleo residual de fritura, ácidos graxos livres, escuma de caixas de gordura e esgoto sanitário, 3. utilizados como matériasprimas para a geração de biodiesel, podem contribuir, significativamente, para a redução dos custos de produção, além de caracterizar o processo como um tratamento sanitário.
O que fazer com a escuma? 1.

Aproveitamento para a produção de biodiesel: integra saneamento ambiental e geração de energia limpa.

2.

3.

4.

Objetivo: Quantificar e caracterizar físico-quimicamente os óleos e graxas residuais, tal como o potencial biodiesel produzido.

Fonte: Os autores 
A UA no Quadro 2 é composta pelo trecho do AOP e o slide (com seu respectivo número de identificação, slide 5). Os números em negrito destacados dizem respeito ao uso de operações de retextualização. Os sublinhados, em conjunto com os números em negrito, no trecho do AOP, indicam o conteúdo que foi utilizado como base para a retextualização. Assim, nesse exemplo os números 2. e 3. no slide estão relacionados com o uso de operações de retextualizações a partir dos conteúdos sublinhados e realçados com os números correspondentes 2. e 3. no trecho do AOP. Há casos em que o número em negrito indicado no slide não tem correspondência com nenhum número no trecho do AOP. Isso significa que o aluno utilizou uma operação de retextualização sem levar em consideração estritamente o conteúdo presente no AOP. Por exemplo, os números 1. e 4. no slide 5 indicam o uso de operações de retextualização, as quais não se baseiam diretamente no conteúdo do AOP.

A discussão dos resultados ocorreu com base em trabalhos que tratam do gênero EO, de processos de retextualização e de compreensão textual, apresentados brevemente no tópico a seguir.

\section{REFERENCIAIS TEÓRICOS}

\subsection{Gênero exposição oral}

Os gêneros apresentam padrões comunicativos empregados pela sociedade, que são tomados como modelos comunicativos globais, a partir da representação de um conhecimento socializado que se dá em situações concretas (BAKHTIN, 1979). Assim, em uma EO, os expositores e os espectadores partem de uma relação assimétrica, na qual o expositor atua no papel de especialista, enquanto os espectadores se mostram aptos ao aprendizado da temática que será abordada.

Nessas circunstâncias, faz parte do papel do expositor diminuir a assimetria entre ele e a plateia, tomando por base as expectativas e interesses dessa última. Ainda no que se refere à caracterização do gênero EO, Dolz et al. (2004) definem a EO como um gênero textual público, formal e específico, no qual um expositor tem a 
função de se dirigir ao público de maneira estruturada para lhe transmitir informações.

Além disso, os autores sugerem que ao ensinar EO para os estudantes é necessário construir uma sequência de atividades levando-se em consideração três dimensões: a situação de comunicação, as características linguísticas e a organização interna da exposição. A situação de comunicação ocorre por meio da exposição realizada em sala de aula, sendo que deve ficar explícito para o aluno expositor o seu papel de especialista, de forma que ele tome consciência acerca deste e possa guiar o seu próprio comportamento. As características linguísticas podem ser apresentadas por meio do sistema textual da EO, ou seja, coesão temática (articulação entre as partes temáticas); sinalização do texto (distinção entre as partes primárias e secundárias; entre as explicações e descrições; entre os desenvolvimentos de conclusões em forma de resumo e as sínteses); introdução de exemplos e reformulações.

Nessa perspectiva, Dolz et al. (2004) propõem que os expositores memorizem as falas, de forma que esta seja espontânea. Assim, é relevante que sejam ensinados aos estudantes como preparar uma EO sem utilizar o recurso da leitura, mas sim, apoios diversos, como, por exemplo, gráficos, anotações e citações. Por fim, a organização interna da exposição diz respeito à capacidade de planejamento de um texto e à consideração das partes inerentes à EO: abertura; introdução ao tema; apresentação do plano; desenvolvimento e encadeamento dos diferentes temas; recapitulação e síntese; conclusão; encerramento.

Neste artigo as referidas considerações foram empregadas para subsidiar a discussão sobre como os estudantes modificaram o texto base do AOP para a EO e quais recursos foram utilizados para tal.

\subsection{Processos de retextualização}

Segundo Marcuschi (2010), a retextualização é um processo natural que ocorre não somente na área de ensino ou pesquisa, mas também no cotidiano, uma vez que a todo o momento textos são reformulados em uma vasta variação de registros, gêneros textuais, níveis linguísticos e estilos. Por exemplo, ao se fazer um relato sobre 
o que alguém disse ou até mesmo quando são produzidas citações indiretas, uma fala está sendo transformada, recriada, reformulada e modificada em outra.

Na esfera acadêmica, o conteúdo retextualizado de um gênero para outro não perde a base informacional estabelecida pelo autor do texto base. Tomando as possíveis combinações entre fala e escrita, a retextualização pode ser efetuada de quatro formas distintas, como ilustra o Quadro 3.

Quadro 3 - Combinações possíveis entre fala e escrita por meio do processo de retextualização

\begin{tabular}{|l|c|lll|}
\hline \multicolumn{2}{|c|}{ Retextualizações possíveis } & \multicolumn{3}{c|}{ Exemplo } \\
\hline 1. Fala & Escrita & 1. Entrevista oral & Entrevista impressa \\
\hline 2. Fala & Fala & 2. Conferência & $\begin{array}{l}\text { Tradução } \\
\text { simultânea }\end{array}$ \\
\hline 3.Escrita & & Fala & 3. Texto escrito & Exposição oral \\
\hline 4. Escrita & Escrita & 4. Texto escrito & & Resumo escrito \\
\hline
\end{tabular}

Fonte: Marcuschi, 2010, p. 48.

No âmbito desta pesquisa, foram estudadas as retextualizações do texto escrito para os slides da EO, que pode ser considerado como outro texto escrito, conforme o exemplo 4 do Quadro 3.

Cabe destacar que Marcuschi (2010) aponta quatro variáveis presentes na retextualização: o propósito (no presente trabalho, o AOP foi apresentado aos alunos, que foram solicitados a elaborarem os slides da EO utilizando-o como base); a relação entre o autor do texto original e o seu transformador; a variação tipológica (no presente trabalho, do texto do AOP para a EO, com a mudança de gênero); os processos de formulação, que se referem às estratégias de produção textual pertencentes a cada modalidade. A partir do exposto, a retextualização se mostra por meio de diversas estratégias e se caracteriza como uma atividade consciente.

O autor destaca também aspectos linguístico-textuais-discursivos e cognitivos que pertencem ao processo de retextualização. A Figura 1 ilustra esses aspectos. 
Figura 1 - Quadro de operações linguístico-textuais-discursivas e cognitivas envolvidas no processo de retextualização (MARCUSCHI, 2010)

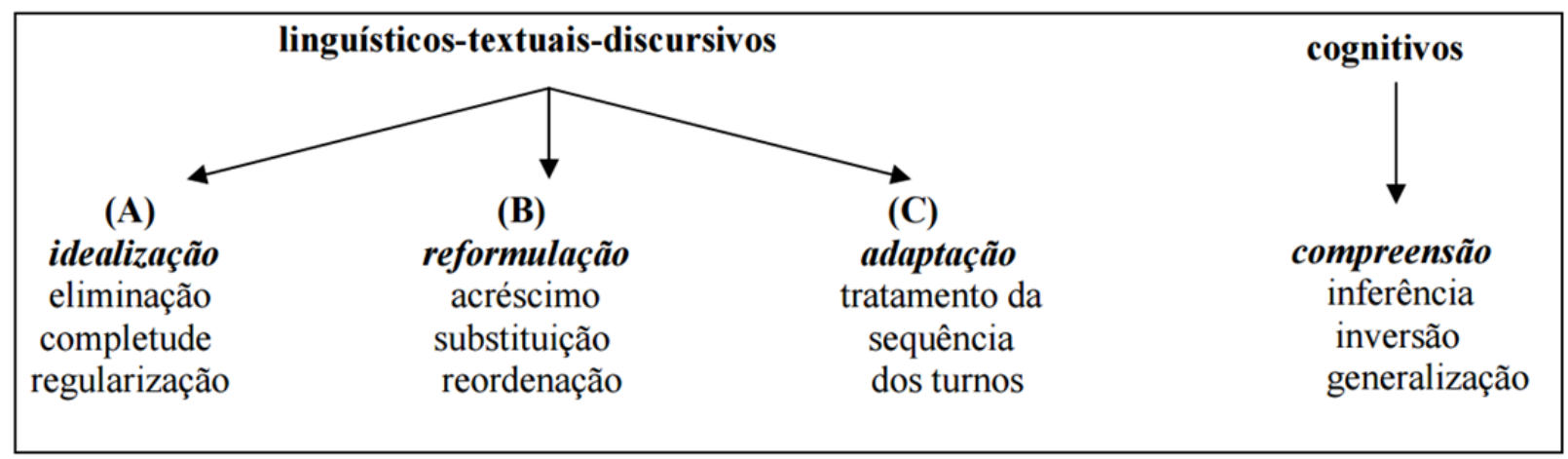

Considerando a Figura 1, a idealização trata das operações que ocorrem na seleção do texto base que será retextualizado. Já as operações referentes à reformulação dizem respeito à re(construção) dessas informações. Por fim, a adaptação trata das operações que ocorrem nos turnos de fala. A compreensão é composta pelas operações cognitivas que ocorrem simultaneamente às outras operações.

As operações de rextualização consideradas neste trabalho (escrita para escrita) foram: acréscimo, eliminação, reordenação tópica, substituição (MARCUSCHI, 2001), condensação, paráfrase e retomada (SILVA, 2011), acréscimo na forma iconográfica, paráfrase na forma iconográfica e retomada na forma iconográfica (QUEIROZ; CABRAL; SILVA, 2017).

As operações mencionadas fornecem a base para investigar o processo de retextualização do AOP para os slides da EO que foi realizado nesta pesquisa. Há nessas atividades de retextualização um aspecto geralmente ignorado e de uma importância imensa. Pois para dizer de outro modo, em outra modalidade ou em outro gênero o que foi dito ou escrito por alguém, deve-se inevitavelmente compreender o que foi que esse alguém disse ou quis dizer. Portanto, antes de qualquer atividade de transformação textual, ocorre uma atividade cognitiva denominada compreensão. Essa atividade, que em geral se ignora ou se dá por 
satisfeita e não problemática, pode ser a fonte de muitos equívocos no plano da coerência no processo de retextualização.

A averiguação das operações de retextualização que foram empregadas na produção dos slides que serviram como material de apoio da EO, a partir do AOP, foi realizada com base nos processos de retextualização mencionados anteriormente e propostos por Marcuschi (2010).

\subsection{Horizontes de compreensão textual}

O diagrama de horizontes de compreensão textual foi publicado na obra intitulada "Produção textual, análise de gêneros e compreensão" e parte da ideia de Dascal (1986), que toma um determinado texto como uma cebola, na qual as camadas mais internas são representadas pelas informações mais objetivas, a serem tratadas sem modificação de conteúdo; as camadas intermediárias são representadas por inferências, nas quais estão os subentendidos e as suposições, que podem sofrer diversas interpretações; as camadas mais externas são representadas pelas crenças e valores pessoais; as camadas das cascas são representadas por extrapolações, nas quais há informações além daquelas dispostas no texto. Nessa perspectiva, Marcuschi (2008) propôs os horizontes de compreensão textual, ilustrados na Figura 2.

Figura 2 - Horizontes de compreensão textual propostos por Marcuschi (2008)

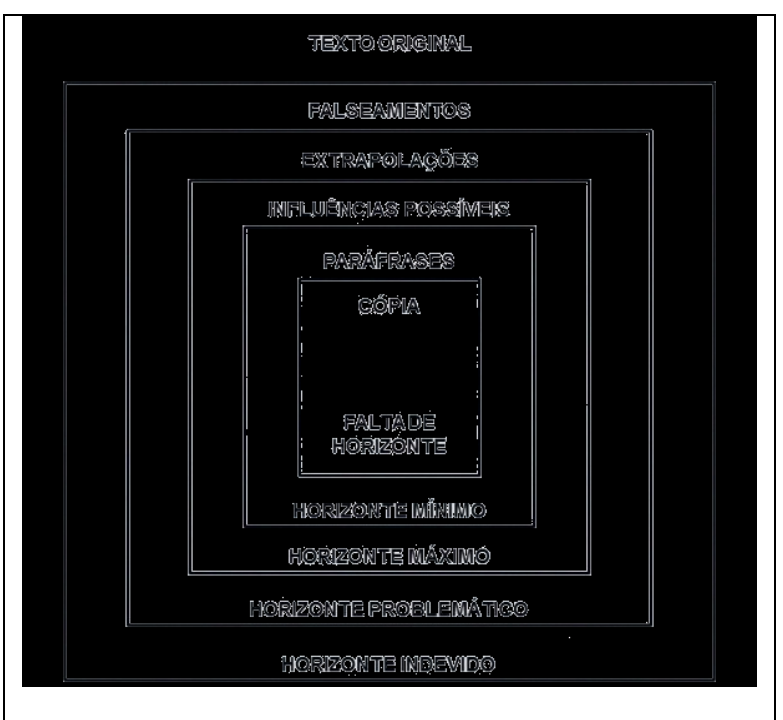


A definição de cada um dos horizontes de compreensão textual consta no Quadro 4.

Quadro 4 - Definição dos horizontes de compreensão textual (MARCUSCHI, 2008)

\begin{tabular}{|c|c|}
\hline Horizonte & Descrição \\
\hline Falta de horizonte & $\begin{array}{l}\text { Leitor repete informações dadas no texto, o que pode indicar (ou não) a sua } \\
\text { compreensão. }\end{array}$ \\
\hline Horizonte mínimo & $\begin{array}{l}\text { Leitor parafraseia informações após selecioná-las, acrescentar e substituir } \\
\text { palavras. }\end{array}$ \\
\hline Horizonte máximo & $\begin{array}{l}\text { Leitor realiza atividades de inferência, de leitura entrelinhas, do agrupamento } \\
\text { de diversas informações do texto, com acréscimo de novas informações e } \\
\text { conhecimentos a elas relacionados. }\end{array}$ \\
\hline $\begin{array}{l}\text { Horizonte } \\
\text { problemático }\end{array}$ & $\begin{array}{l}\text { Leitor insere conhecimentos pessoais às informações dadas no texto, } \\
\text { possibilitando a interpretação do mesmo além do limite de tais informações. }\end{array}$ \\
\hline Horizonte indevido & $\begin{array}{l}\text { Leitor realiza interpretação do texto que conduz ao falseamento das ideias } \\
\text { contidas no mesmo. }\end{array}$ \\
\hline
\end{tabular}

Fonte: Os autores

A averiguação de indícios de compreensão da AOP, considerando as operações de retextualização colocadas em funcionamento, foi pautada no diagrama sobre horizontes de compreensão textual proposto por Marcuschi (2008).

\section{RESULTADOS E DISCUSSÃO}

Nesta seção foram analisadas dezoito UA compostas por excertos dos AOP e os respectivos slides. Estes serviram como material de apoio a uma EO que foi apresentada em dezesseis minutos, a partir da leitura do AOP “Caracterização físicoquímica de resíduos oleosos do saneamento e dos óleos e graxas extraídos visando a conversão em biocombustíveis" (OLIVEIRA et al., 2014).

O AOP discute o potencial uso de resíduos oleosos provenientes de processos de saneamento na geração de biocombustíveis. A partir disso, os autores propõem análises de caracterização de quatro resíduos oleosos e determinação da composição visando conversão em biodiesel. Os resultados demonstraram que as amostras 
caracterizadas apresentaram elevados níveis de óleos e graxas, consequentemente podendo ser aproveitados para a produção de biocombustíveis.

Na Tabela 2 é possível verificar o número total de ocorrências de cada operação de retextualização e de cada horizonte de leitura revelado na análise.

Tabela 2 - Frequência do uso das operações de retextualização na elaboração dos slides e horizontes de compreensão textual revelados em cada caso

\begin{tabular}{lcccccc}
\hline $\begin{array}{l}\text { Operações de } \\
\text { Retextualização }\end{array}$ & $\begin{array}{c}\text { Falta de } \\
\text { horizonte }\end{array}$ & $\begin{array}{c}\text { Horizonte } \\
\text { mínimo }\end{array}$ & $\begin{array}{c}\text { Horizonte } \\
\text { máximo }\end{array}$ & $\begin{array}{c}\text { Horizonte } \\
\text { problemático }\end{array}$ & $\begin{array}{c}\text { Horizonte } \\
\text { indevido }\end{array}$ & Total \\
\hline Acréscimo & - & - & 11 & 1 & - & 12 \\
Eliminação & - & 15 & 8 & - & 1 & 24 \\
Reordenação & - & 4 & - & - & - & 5 \\
Substituição & - & 6 & 1 & - & 1 & 8 \\
Condensação & - & 1 & 3 & - & - & 4 \\
Retomada & 5 & - & - & - & - & 5 \\
Paráfrase & - & 6 & 1 & - & - & 7 \\
Total & 5 & 32 & 24 & 1 & 2 & - \\
\hline
\end{tabular}

A análise da Tabela 2 evidencia que o aluno expositor do grupo em questão manifestou todos os horizontes de compreensão textual reconhecidos por Marcuschi (2008). Houve predominância de compreensão no horizonte mínimo (32 ocorrências), ao passo que a menor frequência esteve relacionada ao horizonte problemático (uma ocorrência). A compreensão no horizonte máximo aparece frequentemente (24 ocorrências), porém não se destaca se comparado ao horizonte mínimo. Embora os números não sejam expressivos, a falta de horizonte (cinco ocorrências) e o horizonte indevido (duas ocorrências) também apareceram na análise.

No que diz respeito à retextualização na passagem do texto base para os slides, a operação de eliminação foi a mais comum (24 ocorrências), enquanto que a condensação foi a menos recorrente (quatro ocorrências). A quantidade de usos das operações de acréscimo (doze ocorrências), substituição (oito ocorrências) e paráfrase (sete ocorrências) revela que as mesmas foram significativas na elaboração da EO. A 
reordenação e a retomada não foram estratégias que se destacaram na análise, no entanto, serão mencionadas ao longo da discussão.

A seguir, são discutidas as UA levando em consideração perspectivas que apontaram para determinados horizontes de compreensão, os quais foram identificadas com base nas operações de retextualização colocadas em funcionamento. A discussão ocorre em ordem decrescente do nível de complexidade dos horizontes de compreensão, sendo discutidas inicialmente as UA referentes à compreensão no horizonte máximo e, por último, as UA referentes à compreensão no horizonte indevido.

\subsection{Horizonte máximo}

Conforme mencionado anteriormente, o processo de compreensão no horizonte máximo considera atividades inferenciais, ou seja, atividades que geram sentido pela reunião de várias informações do texto, ou pela inserção de conhecimentos pessoais e informações que não constam no texto base. Em geral, exigem processos cognitivos de alto nível, como capacidade de realizar inferências, habilidades linguísticas gerais e conhecimento de mundo (MARCUSCHI, 2008).

Verificamos 24 ocorrências de compreensão textual no horizonte máximo (Tabela 1), sendo o segundo horizonte mais recorrente. O horizonte máximo esteve relacionado a operações de acréscimo (onze), eliminação (oito), condensação (três), substituição (uma) e paráfrase (uma). Assim, dentre as mencionadas, a operação mais frequente foi a de acréscimo, enquanto que as menos frequentes foram a de substituição e paráfrase.

O Quadro 5 ilustra um exemplo de compreensão no horizonte máximo relacionado ao uso da operação de acréscimo. O conteúdo do slide 1 trata daabertura da EO. 
Quadro 5 - UA referente ao uso da operação de acréscimo: compreensão no horizonte máximo

\section{Trecho do AOP}

Quim. Nova, Vol. 37, No. 4, 597-602, 2014 (1)

Caracterização físico-química de resíduos oleosos do saneamento e dos óleos e graxas extraídos visando a conversão em biocombustíveis

\section{Slide 1}

\begin{tabular}{|c|c|}
\hline \multicolumn{2}{|c|}{$\begin{array}{l}\text { Caracterização Fisico-Quimica de Residuos } \\
\text { Oleosos do Saneamento e dos Óleos e Graxas } \\
\text { Extraídos Visando a Conversão em } \\
\text { Biocombustiveis }\end{array}$} \\
\hline & 1. \\
\hline Grupo & \\
\hline
\end{tabular}

Fonte: Os autores

A primeira perspectiva para identificação do horizonte máximo é exemplificada na UA do Quadro 5, com a realização de uma atividade inferencial por parte do aluno a partir da inserção de uma imagem associada a um conteúdo que não constava no texto base. De acordo com Dell'Isola (2007), a inferência é um processo cognitivo que gera uma informação semântica nova, a partir de uma informação semântica anterior, em determinado contexto. Adicionalmente, observa-se que a imagem inserida no slide apresenta características que possivelmente revelam a opinião do aluno expositor sobre o conteúdo presente no AOP. Ou seja, o aluno buscou conhecimentos adquiridos pela experiência de vida para complementar a apresentação, indicando compreensão no horizonte máximo.

No referido exemplo, foi utilizada a operação de acréscimo na forma iconográfica, apontado em 1. (Quadro 5), em virtude da adição de uma figura. Carneiro (1997) define a imagem como representação visual, real ou analógica de um ser, fenômeno ou objeto, que normalmente se apresenta em oposição ao texto escrito, no qual a oposição se situa entre a imagem e linguagem, ou seja, signo linguístico e signo não linguístico. Em resumo, a imagem pode significar uma complementação do sentido do texto. Partindo desse pressuposto, o aluno, ao buscar uma imagem suplementar, trouxe um novo sentido do texto à apresentação. 
Considerando que o slide 1 corresponde à abertura da EO, a adição da imagem, supostamente serviu como estratégia para chamar a atenção dos espectadores. Para Dolz et al. (2004) este é o momento de despertar o interesse do público.

O Quadro 6 ilustra um exemplo de compreensão no horizonte máximo relacionado ao uso das operações de acréscimo e condensação precedidas por eliminação. O conteúdo do slide 13 apresenta um esclarecimento sobre os fatores que inviabilizam o uso de resíduos oleosos do saneamento para a produção de biodiesel.

Quadro 6 - UA referente ao uso das operações de acréscimo e condensação precedidas por eliminação: compreensão no horizonte máximo

\section{Trecho do AOP}

Slide 13

2. Essa acidez elevada pode inviabilizar o uso destes resíduos como matéria-prima para a produção de biodiesel em reações de alcoólise com catalisador básico, pois a transesterificação alcalina exige que o óleo vegetal seja isento de umidade e com baixo teor de acidez (ácidos graxos livres não podendo exceder $1 \%$ ). Isto devido à alta capacidade da base em reagir com os ácidos graxos livres, formando sabão e água, o que dificulta a separação e purificação do biodiesel.

4. O teor de umidade obtido também foi elevado se comparado a amostras de óleos recém refinados,

Possiveis pontos problemáticos: 1 .

- Alto indice de acidez

Causado por ácidos graxos livres. 2.

$\mathrm{R}-\mathrm{C}_{\mathrm{O}-\mathrm{R}^{\prime}}^{\mathrm{O}}+\mathrm{H} 2 \mathrm{O} \longrightarrow \mathrm{R}-\mathrm{C}_{\mathrm{O}-\mathrm{H}^{\prime}}^{\mathrm{O}}+\mathrm{R}-\mathrm{O}-\mathrm{H} \underset{\text { Hidrólise }}{\text { Reaço de }} \mathbf{3}$.

Fonto : wmw portalcloprotossor moc gov br

Em alcoólise com catalisador básico pode ocorrer a reaçăo de saponificação.

- Teor relativamente alto de umidade.

4. os quais apresentam teores de umidade média inferior a $0,5 \%$.

Fonte: Os autores

A segunda perspectiva para identificação do horizonte máximo é exemplificada na UA do Quadro 6, com a realização de uma atividade inferencial por parte do aluno, a partir da identificação e reunião de informações do texto base a respeito dos fatores mencionados, além do acréscimo de informações escritas que não constam no texto base. Nesse sentido, os processos envolvidos exigiram o conjunto de informações do próprio texto e o conjunto de conhecimentos prévios que foram ativados para guiar o aluno na interpretação ativa e crítica das informações textuais. 
O acréscimo, indicado pelo número 1. (Quadro 6), corresponde à adição de informação que não consta no AOP, sendo o título "possíveis pontos problemáticos". Tais palavras denotam, possivelmente, a intenção do expositor em potencializar o entendimento dos espectadores sobre o assunto. Para isso, o aluno empregou conhecimentos e estratégias que excedem a mera combinação de significados lexicais individuais, elaborando uma representação mental do conteúdo proposicional das mensagens. Segundo Dolz et al. (2004), a atitude por parte do expositor revela um trabalho significativo, que envolve o planejamento, a antecipação e a consideração aos espectadores.

O acréscimo na forma iconográfica, indicado no Quadro 6 por 3., representa a reação de hidrólise de um éster formando um ácido e um álcool. A informação está contida no texto base, porém é implícita e ocorre na forma descritiva. Dessa maneira, verifica-se o uso de ilustração na substituição do texto escrito, com potencialidade para facilitar a compreensão do mesmo. Em relação ao processo de compreensão do conhecimento químico, Johnstone (2000) afirma que existem três diferentes níveis de representação: macroscópico, submicroscópico e simbólico. No nível de representação macroscópico, os fenômenos são observáveis e, no submicroscópico, o fenômeno químico pode ser explicado por meio do arranjo e movimento de moléculas, átomos, íons, elétrons etc. A química no nível simbólico refere-se tanto a representações simbólicas quanto a símbolos químicos como, por exemplo, fórmulas, equações e estruturas. Desse modo, o aluno buscou explicitar o conteúdo presente no texto base no nível simbólico e obteve sucesso na medida em que retextualizou o trecho do AOP com a adição da equação química pertinente. Nesse cenário, o estudante revelou compreensão do conhecimento químico e do texto base. Observase, portanto, uma leitura inferencial por parte do aluno expositor, a partir da reunião de várias informações do texto e da inserção de informações e conhecimentos que são relacionados a ele.

As condensações precedidas de eliminação, apontadas no Quadro 6 pelos números 2. e 4. foram utilizadas pelo aluno expositor com o intuito de resumir o conteúdo do AOP para criação de tópicos. De acordo com van Dijk e Kintsch (1983), a 
capacidade de resumir textos é considerada uma manifestação do processo de compreensão e também indicativa da competência discursiva do leitor-resumidor, uma vez que o sucesso dessa na utilização das regras de redução semântica depende da sua capacidade em avaliar as informações do texto em termos da estrutura global do mesmo. Logo, é plausível inferir que omissões de informações do texto base, quando malsucedidas, podem gerar o entendimento errôneo por parte dos espectadores. No exemplo dado houve redução das informações do AOP, porém, manteve-se a base informacional, com a frase retextualizada caracterizando-se como uma reformulação do conteúdo e apresentando um menor número de estruturas sintáticas se comparadas ao texto base.

O Quadro 7 ilustra um exemplo de compreensão no horizonte máximo relacionado ao uso das operações de acréscimo, condensação e eliminação. O conteúdo do slide 5 apresenta uma discussão sobre o aproveitamento da escuma para a produção do biodiesel e as vantagens da mesma, como saneamento ambiental e geração de energia limpa.

Quadro 7 - UA referente ao uso de operações de acréscimo, condensação e eliminação: compreensão no horizonte máximo

\section{Trecho do AOP}

Slide 5

2. Devido aos elevados teores de OGRs, a escuma apresenta alto potencial a ser utilizada como matéria-prima na produção de biodiesel.

(...)

OGRs como o óleo residual de fritura, ácidos graxos livres, escuma de caixas de gordura e esgoto sanitário, 3. utilizados como matérias-primas para a geração de biodiesel, podem contribuir, significativamente, para a redução dos custos de produção, além de caracterizar o processo como um tratamento sanitário.

\section{O que fazer com a escuma? 1.}

2. Aproveitamento para a produção de biodiesel: integra saneamento ambiental e geração de energia limpa.

3.

4.

Objetivo: Quantificar e caracterizar físico-quimicamente os óleos e graxas residuais, tal como o potencial biodiesel produzido.

Fonte: os autores 
A terceira perspectiva para identificação do horizonte máximo é exemplificada na UA do Quadro 7, com a realização de uma atividade inferencial a partir da reunião de componentes textuais e da adição de componentes que vão além do texto base e funcionam como premissas para se chegar a outra informação. Nota-se que a exposição do slide se inicia com uma questão não pertencente ao texto, construída por meio de uma inferência. Na sequência, o aluno expõe a solução da pergunta em um tópico, realizando condensação precedida de eliminação de várias informações do AOP, sem que ocorra eliminação de elementos essenciais.

Com relação às operações de acréscimo, indicadas no Quadro 7 pelos números 1. e 4., foi identificada a adição de informações que não constam explicitamente no AOP, como a questão "o que fazer com a escuma?" e a expressão "energia limpa". Segundo Spinillo e Mahon (2007), geralmente um texto escrito não apresenta de forma explícita todas as informações necessárias para a elaboração que leva à compreensão, sendo que quem o produz pressupõe que as informações serão recuperadas pelo leitor de alguma forma. O aluno resgatou as informações e usou-as para informar, esclarecer ou potencializar os conhecimentos dos espectadores com o intuito de reduzir a assimetria inicial de conhecimentos em relação aos ouvintes.

As condensações precedidas por eliminações, apontadas no Quadro 7 pelos números 2. e 3. foram realizadas para resumir em duas expressões ("aproveitamento para a produção de biodiesel" e "saneamento ambiental") ideias contidas em dois parágrafos do texto base. Foram realizadas eliminações léxico-sintáticas por meio da omissão de informações que podem ser recuperadas a partir do uso do slide durante a EO. Dessa forma, a compreensão do texto nesses casos é essencial, visto que há a elaboração de um novo texto a partir do primeiro.

As operações evidenciadas nos exemplos serviram de base para a realização de inferências, ação que se revelou indispensável para que os alunos alcançassem a compreensão no horizonte máximo. Além do mais, as inferências foram realizadas para fins distintos, o que possibilitou a sua análise em diferentes perspectivas.

Segundo Marcuschi (2008), o grau de complexidade de compreensão textual no horizonte máximo é alto. Nesse sentido, o resultado obtido em relação ao número 
total de ocorrências de compreensão nesse horizonte (24) é positivamente surpreendente, uma vez que esse horizonte foi atingido diversas vezes.

Acredita-se que a dificuldade em se alcançar o horizonte máximo se dá em virtude da exigência de ações complexas, como capacidade de realizar inferências, habilidades linguísticas gerais e fatores como conhecimentos do aluno, gênero e forma de textualização.

\subsection{Horizonte mínimo}

Conforme mencionado anteriormente, o horizonte mínimo de leitura corresponde à leitura parafrástica, ou seja, repetição de informações do texto base com outras palavras, termos ou expressões. O horizonte mínimo nos slides do grupo em questão foi o mais numeroso, com 32 ocorrências, e esteve relacionado a operações de eliminação (quinze), reordenação (quatro), substituição (seis), condensação (uma) e paráfrase (seis). A operação mais recorrente foi a de eliminação e a menos recorrente foi a de condensação.

O Quadro 8 ilustra um exemplo de compreensão no horizonte mínimo relacionado ao uso de operações de eliminação, substituição e reordenação. O conteúdo do slide 4 apresenta a introdução da EO por meio da inserção de uma questão inicial.

Quadro 8 - UA referente ao uso de operações de eliminação, substituição e reordenação: compreensão no horizonte mínimo

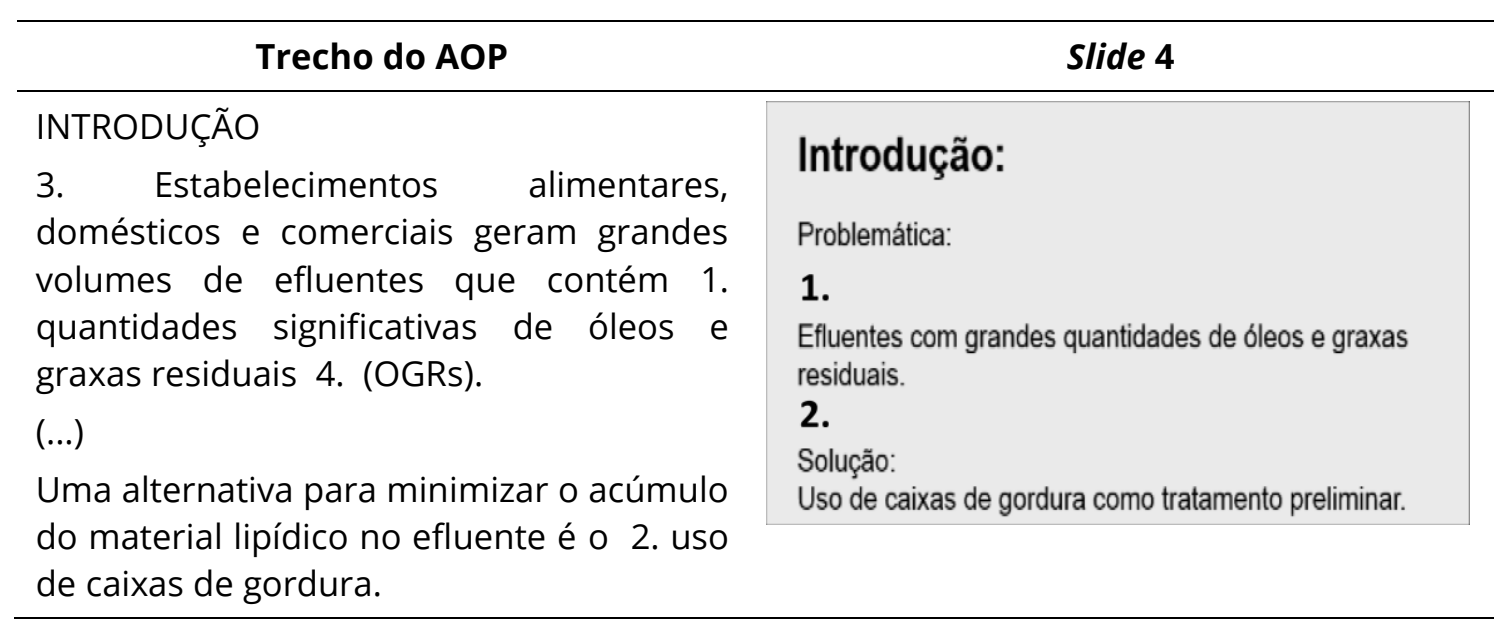

Fonte: Os autores 
A primeira perspectiva para identificação do horizonte mínimo é exemplificada na UA do Quadro 8, a partir da leitura parafrástica do texto, visto que houve reconhecimento e reprodução do conteúdo por meio de outras palavras na introdução ao tema. A substituição, indicada no Quadro 8 pelo número 1., aponta a utilização da operação de substituição no momento em que o estudante modifica a expressão "quantidades significativas" por "grandes quantidades". Nesse caso, a substituição revela a preocupação com o tratamento estilístico a ser dado no texto para o slide por parte do aluno expositor visando uma maior formalidade na apresentação. De acordo com Oakhill e Cain (2007), fatores como reconhecimento de palavras se referem à leitura eficiente e precisam estar presentes para que a compreensão textual ocorra.

O uso da reordenação de ideias, expresso no Quadro 8 pelo número 2., desloca a expressão "uso de caixas de gordura" para o início do tópico. A operação em questão diz respeito à qualidade da EO, pois interfere no estilo, na ordem dos tópicos e na estratégia de argumentação utilizada pelo aluno expositor. Dessa forma, há influência direta na compreensão que o aluno apresenta acerca do texto base.

As operações de eliminação, indicadas no Quadro 8 pelos números 3. (estabelecimentos alimentares, domésticos e comerciais que geram grandes volumes) e 4. (ORGs), podem ter sido utilizadas para diminuir o volume de texto na elaboração dos slides. Segundo Oliveira e Queiroz (2017), para a elaboração de uma "boa exposição oral", os autores devem evitar escrever textos ou muitos tópicos por slide ou transparência.

O Quadro 9 ilustra um exemplo de compreensão no horizonte mínimo relacionado ao uso de operações de eliminação, reordenação e substituição. O conteúdo do slide 16 apresenta o desfecho da EO.

A segunda perspectiva para identificação do horizonte mínimo é exemplificada na UA do Quadro 9, a partir da leitura parafrástica do texto, uma vez que o aluno expositor se mantém coerente com o que é proposto no texto base, no entanto, não questiona as ideias apresentadas e se limita à mera repetição. Observa-se que o estudante elabora a conclusão baseado em dois parágrafos inseridos na seção 
Conclusão do AOP. Para isso, foram empregadas operações de reordenação, eliminação e substituição.

Quadro 9 - UA referente ao uso de operações de eliminação, reordenação e substituição: compreensão no horizonte mínimo

\section{Trecho do AOP}

1. sendo a catálise homogênea ácida ou catálise heterogênea 3. indicada para 2. tal processo.

(...) esta mistura de ácidos graxos saturados e insaturados 4. pode gerar um biodiesel com 5 . excelente qualidade.

\section{Slide 16}

\section{Conclusão:}

Os resíduos oleosos são uma matéria prima viável e ambientalmente benéfica.

No entanto, a análise realizada demonstra a inviabilidade da catálise alcalina. Sendo as mais apropriadas a catálise homogênea ácida ou a catálise heterogênea. 1. 3.

4. Ainda, devido à grande variedade de ácidos graxos, há a possibilidade de gerar um biodiesel de ótima qualidade.

Fonte: Os autores

Conforme ilustrado no Quadro 9 em 1., o leitor modifica a ordem das ideias apresentadas no texto base. Nesse sentido, a reordenação não prejudica o sentido original, uma vez que as palavras “a catálise homogênea ácida ou catálise heterogênea" e a expressão já substituída "as mais apropriadas" possuem o mesmo nível de importância e podem, assim, ser alteradas em sua ordem. Na retextualização de textos científicos é comum que os alunos realizem a reordenação de informações dispostas no texto base, estabelecendo modificações na estrutura linguística e na forma de expressão, mas mantendo o conteúdo. Isso se deve, provavelmente, à sua falta de audácia em modificar o texto de outro autor, considerando que o texto do AOP foi escrito por pessoas autorizadas pela comunidade científica, enquanto que o estudante, em sua condição de aprendiz, não se vê reconhecido como tal.

A eliminação de "tal processo", apontada no Quadro 9 em 2., supostamente foi realizada como forma de diminuir o volume de texto para elaboração do slide, apoiado no fato de que o processo já havia sido mencionado em trecho anterior. As substituições de "indicada" por "apropriada", "pode gerar" por "há a possibilidade de gerar" e "excelente" por “ótima”, mostradas no Quadro 9 em 3., 4. e 5., são 
semanticamente equivalentes de forma que não houve prejuízos à base informacional do AOP. Nesse contexto, a interferência do leitor é mínima, pois utiliza palavras distintas para repetir as mesmas informações do texto base.

O Quadro 10 ilustra um exemplo de compreensão no horizonte mínimo relacionado ao uso de operações de paráfrase, eliminação, substituição e reordenação. O conteúdo do slide 9 refere-se à seção Materiais e Métodos do AOP, seção na qual são apresentados os materiais utilizados e procedimentos realizados nos experimentos.

Quadro 10 - UA referente ao uso de operações de paráfrase, eliminação, substituição e reordenação: compreensão no horizonte mínimo

\section{Trecho do AOP}

Slide 9

1. 1.a) seguida de centrifugação a $3.000 \mathrm{rpm}$ por 5 minutos 1.b) para a retirada de materiais particulados e eventuais impurezas. O volume final de óleo foi medido por gravimetria para quantificação

Composição de ácidos graxos

2. Após realizar procedimentos de saponificação-esterificação,26 a composição química 3. em ácidos graxos dos OGRs 5. 6. foi detectada e 4. quantificada por cromatografia líquida de alta eficiência (CLAE).

Fonte: Os autores

A terceira perspectiva para identificação do horizonte mínimo é exemplificada na UA do Quadro 10, com a construção de um fluxograma por meio da seleção e organização de informações presentes no AOP. Nesse processo, o aluno expositor não discute sobre as técnicas e materiais empregados pelo autor, ou seja, apenas reproduz o conteúdo de outra forma. Isso foi realizado pela utilização de paráfrase e operações de acréscimo, eliminação, substituição e reordenação.

A paráfrase, proposta por Silva (2011) a partir da definição de Marcuschi (2010), trata da reescrita de fragmentos do texto base de uma forma linguística para outra similar semanticamente à original. A operação de paráfrase, representada no Quadro 10 por 1., é constituída de substituição de "seguida de" por "submeter" (expressa em 
1.a)) e de eliminação de "para a retirada de materiais particulados e eventuais impurezas" (exposta em 1.b)). A substituição foi realizada para adequar o enunciado à EO, enquanto que a eliminação foi usada para resumir informações do texto base. Assim, constata-se a integração de estratégias formando um novo texto sem alteração do sentido original

Nas eliminações de "após realizar", "em ácidos graxos dos OGRs" e "quantificada", indicadas no Quadro 10 por 2, 3., 4., o aluno expositor exclui informações que não considera relevante para a construção do slide, podendo recuperá-las durante a EO. A substituição de "foi detectada" por "determinação", apontada no Quadro 10 por 5., é semelhante em sentido, sendo assim, o aluno revela compreensão no horizonte mínimo. A reordenação, apontada no Quadro 10 por 6., traz o termo "foi detectada" (substituído no slide por "determinação") para o início do tópico. Há, nesse sentido, compreensão no horizonte mínimo uma vez que a reordenação não prejudica o sentido original do texto base, ou seja, as informações possuem a mesma relevância e podem ser modificadas em sua ordem.

As operações evidenciadas nos exemplos serviram de fundamento para a repetição das mesmas informações do texto base em outras palavras, termos ou expressões, ação que se revelou indispensável para que os alunos alcançassem a compreensão no horizonte mínimo. Além do mais, as repetições foram realizadas para fins distintos, o que possibilitou a sua análise em diferentes perspectivas.

A compreensão no horizonte mínimo foi a mais recorrente, o que pode estar relacionado ao receio dos estudantes em cometer erros a partir da inserção de conhecimentos pessoais e informações que não constam no texto base, visto que os equívocos supostamente causam prejuízo nas avaliações às quais são submetidos. Mesmo assim, Marcuschi (2008) aponta que a repetição de ideias do texto base em outro vocábulo pode indicar compreensão textual.

\subsection{Falta de horizonte}

A falta de horizonte está associada apenas à cópia das informações do texto. Nesse sentido, a atividade do leitor se reduz à mera repetição e não há reflexão sobre 
as informações veiculadas no texto (MARCUSHI, 2008) A falta de horizonte nos slides do grupo em questão foi escassamente identificada, com apenas cinco ocorrências, e esteve relacionado somente à operação de retomada.

O Quadro 11 ilustra um exemplo relacionado ao uso da operação de retomada, a partir da qual se discute a única perspectiva para identificação da falta de horizonte. $\mathrm{O}$ conteúdo do slide 14 diz respeito aos resultados apresentados no AOP.

Quadro 11 - UA referente ao uso de operação de retomada: compreensão na falta de horizonte

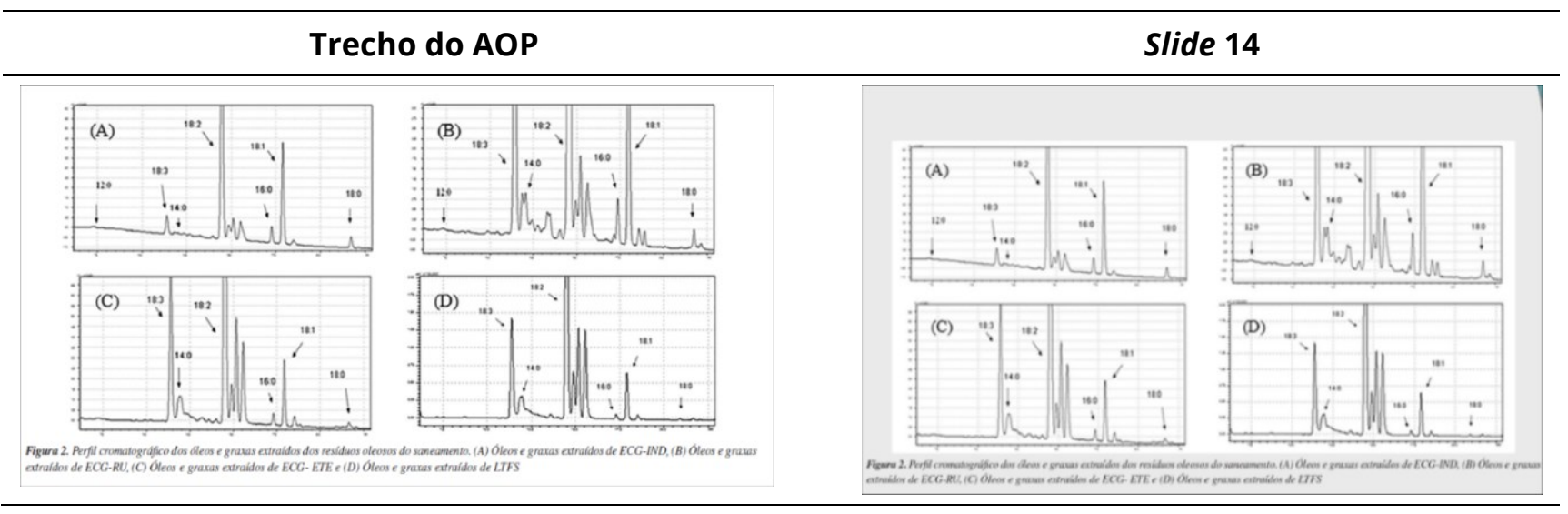

Fonte: os autores

É identificada na UA do Quadro 11 a cópia da informação do texto base, sendo que 0 aluno expositor utiliza a mesma tabela e legenda presentes no AOP. Nesse caso, ocorre o uso da operação de retomada de dois tipos, a retomada textual e a retomada na forma iconográfica. A retomada textual refere-se ao uso da legenda original da figura, enquanto que a retomada na forma iconográfica diz respeito ao uso da própria figura do AOP no slide.

Todas as retomadas foram realizadas por meio da cópia, de modo que não ocorreram alterações na fonte utilizada, no número da figura, dentre outras modificações que poderiam ser feitas em caso de reconstrução da mesma por parte do aluno expositor. Assim, tomando por base a metodologia em voga neste trabalho, que considera a análise apenas da retextualização escrita para escrita (AOP para slides), conclui-se que o aluno assumiu um papel passivo, pois abstraiu o sentido do texto e o transpôs para outro lugar. No entanto, tal assertiva poderia não ser 
verdadeira, caso a análise abarcasse também a retextualização escrita para fala, na qual se consideraria a fala do aluno frente ao slide 14 , o que poderia indicar a compreensão textual em outro tipo de horizonte. Nessa perspectiva, é possível apontar uma limitação da metodologia aqui adotada, no que diz respeito à tessitura de considerações sobre a falta de horizonte de compreensão textual, na perspectiva de Marcushi (2008).

Mesmo considerando a referida limitação da metodologia, poucas foram as UA que indicaram falta de horizonte. Essa constatação não é corroborada por Santos (2006), que afirma que, usualmente, universitários se limitam a somente repetir o conteúdo presente na literatura, sem realizar analises críticas e próprias. Essa operação de repetição é reveladora de limitado domínio da discursividade e uma prática social em total submissão à prática discursiva.

\subsection{Horizonte problemático}

O horizonte problemático diz respeito à extrapolação por meio de conhecimentos pessoais, ou seja, o leitor interpreta o texto além os limites das informações que ele contém (MARCUSHI, 2008). Embora esse horizonte não seja considerado como inadequado, se situa no limite da interpretabilidade. A compreensão nesse horizonte tem caráter pessoal e é tida como "opinião pessoal" do estudante. Uma única ocorrência de compreensão no horizonte problemático foi verificada nos slides do grupo em questão, associada à operação de acréscimo.

O Quadro 12 ilustra um exemplo da compreensão no horizonte problemático, relacionado ao uso da operação de retomada, a partir da qual se discute uma única perspectiva para identificação do horizonte problemático. A UA referente ao Quadro 12 já foi mencionada anteriormente (Quadro 8), durante a discussão da compreensão no horizonte máximo, contudo, nela também se identifica o horizonte problemático. No slide 4, o aluno expositor busca esclarecer uma solução para a problemática evidenciada no AOP: efluentes com grandes quantidades de óleos e graxas residuais. A solução dada pelo aluno é o uso de caixas de gordura como tratamento preliminar. 
Quadro 12 - UA referente ao uso da operação de acréscimo: compreensão no horizonte problemático

\section{Trecho do AOP}

Uma alternativa para minimizar o acúmulo do material lipídico no efluente é o uso de caixas de gordura.

\section{Slide 4}

\author{
Introdução: \\ Problemática: \\ Efluentes com grandes quantidades de óleos e graxas \\ residuais.
}

Solução: 1.

Uso de caixas de gordura como tratamento preliminar.

Fonte: os autores

É identificada na UA do Quadro 12 a extrapolação das informações do texto. O aluno expositor, ao supor o uso de caixas de gordura como tratamento preliminar para o problema apresentado, presume um conteúdo que não condiz com o exposto no AOP, o qual cita que o uso de caixas de gordura é apenas uma alternativa para minimizar o acúmulo de material lipídico no efluente. De fato, houve extrapolação das informações do texto, visto que a partir do seu ponto de vista, possivelmente o aluno considera o uso de caixas de gordura como solução do problema.

A operação de acréscimo de novas informações textuais, indicada no Quadro 12 por 1., refere-se à adição do termo "solução". Nesse contexto, a adição serviu para ampliar o conteúdo informacional e explicitar uma informação. Dado que se notou valorização da opinião pessoal do expositor sobrepujando a informação do AOP, constata-se o horizonte problemático de compreensão por meio da extrapolação da ideia matriz.

Portanto, os slides do grupo em questão apresentam apenas uma leitura no horizonte problemático, consistindo no uso da operação de acréscimo. Isso indica que em apenas um momento da apresentação houve explícita inadequação da leitura. A estratégia de acréscimo permitiu interpretação incoerente das informações presentes no AOP, sendo que não houve uma interferência crítica, mas uma desconsideração da informação recebida na leitura. 


\title{
4.5 Horizonte indevido
}

Parafraseando Marcuschi (2008), o horizonte indevido é o nível de leitura errônea. É um aspecto que merece destaque pois revela falta de entendimento do conteúdo e dificuldades no emprego de estratégias de leitura.

Foi possível identificar nas UA do grupo em questão duas ocorrências de leitura no horizonte indevido, sendo este um dos horizontes menos recorrentes. O horizonte indevido esteve associado à uma operação de eliminação e à uma de substituição. $O$ Quadro 13 ilustra um exemplo da compreensão no horizonte indevido relacionado ao uso da operação de eliminação. O slide 5 apresenta uma discussão sobre o aproveitamento da escuma para a produção do biodiesel e as vantagens da mesma, além de expor o objetivo do trabalho do AOP.

Quadro 13 - UA referente ao uso da operação de eliminação: compreensão no horizonte indevido

\section{Trecho do AOP}

Slide 5

\begin{abstract}
Assim, o objetivo deste trabalho foi caracterizar quatro resíduos oleosos do saneamento e avaliar os parâmetros físico-químicos dos óleos e graxas extraídos, 1. bem como sua composição em ácidos graxos visando conversão em biodiesel.
\end{abstract}

\section{O que fazer com a escuma?}

Aproveitamento para a produção de biodiesel: integra saneamento ambiental e geração de energia limpa.

Objetivo: Quantificar e caracterizar físico-quimicamente os óleos e graxas residuais, tal como o potencial biodiesel produzido

Fonte: os autores

A primeira perspectiva do horizonte indevido é exemplificada na UA do Quadro 13, a partir da exclusão de informações necessárias para a EO, causando prejuízos à base informacional do AOP. Os autores do artigo mencionam que o objetivo do trabalho foi caracterizar resíduos oleosos e avaliar parâmetros físico-químicos, bem como determinar sua composição em ácidos graxos. Supõe-se que, do ponto de vista do aluno expositor, a última informação não é relevante, o que resultou na sua eliminação, levando à interpretação distorcida e falseamento das ideias do AOP. 
A eliminação de "bem como sua composição em ácidos graxos" por parte do leitor, apontando no Quadro 13 por 1., ocorre, pois foi considerada, provavelmente, como uma informação secundária. A omissão de partes do texto, quando feita aleatoriamente, pode ser altamente prejudicial à manutenção da ideia inicial. Sendo assim, o aluno não nota a distorção realizada ao eliminar trechos do AOP e desvia-se do conteúdo inicialmente proposto pelo autor do texto base.

O Quadro 14 ilustra um exemplo de compreensão no horizonte indevido relacionado ao uso de operação de substituição. A UA nele apresentada já foi mencionada anteriormente (Quadro 7) durante a discussão da compreensão no horizonte mínimo, contudo, nela também se identifica o horizonte indevido. Conforme mencionado, o conteúdo do slide 16 apresenta o desfecho da EO.

Quadro 14 - UA referente ao uso da operação de substituição: compreensão no horizonte indevido

1. Esta mistura de ácidos graxos saturados e insaturados pode gerar um biodiesel com excelente qualidade.

\section{Conclusão:}

Os resíduos oleosos são uma matéria prima viável e ambientalmente benéfica.

No entanto, a análise realizada demonstra a inviabilidade da catálise alcalina. Sendo as mais apropriadas a catálise homogênea ácida ou a catálise heterogênea.

1.

Ainda, devido à grande variedade de ácidos graxos, há a possibilidade de gerar um biodiesel de ótima qualidade.

Fonte: os autores

A segunda perspectiva para identificação do horizonte indevido é exemplificada na UA do Quadro 14, a partir da mudança do conteúdo informacional do texto base, o que acarretou falseamento das ideias presente no mesmo. A modificação sugere que o aluno expositor não compreendeu que o que gera um biodiesel de excelente qualidade é a mistura de ácidos graxos saturados e insaturados, e não a grande variedade de ácidos graxos. 
A substituição "esta mistura de ácidos graxos saturados e insaturados" por "devido à grande variedade de ácidos graxos", indicada por 1., não é equivalente em sentido. Desse modo, possivelmente, o uso da operação foi originado de uma interpretação errônea por parte do leitor, gerando alteração da ideia defendida pelo autor do AOP e consequências para a construção do sentido da apresentação oral.

De acordo com a análise apresentada, a compreensão no horizonte indevido manifestou-se em somente dois momentos durante a EO, portanto foi um horizonte pouco recorrente.

\section{CONCLUSÕES}

Neste trabalho verificou-se que a compreensão textual no horizonte mínimo foi a mais recorrente, em comparação aos demais horizontes. O resultado não é surpreendente e, provavelmente, está relacionado ao receio dos estudantes em cometer erros a partir da inserção nos slides de conhecimentos pessoais e informações que não constavam no texto base. Nessa perspectiva, informações foram parafraseadas a partir da seleção e substituição de palavras presentes no AOP. Mesmo assim, foi possível constatar indícios de compreensão textual coerente nas UA analisadas com relação a esse horizonte e as operações de retextualização colocadas em funcionamento levaram à substituição de palavras de forma alinhada com a base informacional estabelecida no AOP.

A compreensão textual no horizonte máximo também foi uma das mais recorrentes. O resultado é bastante animador, uma vez que o alcance de tal compreensão exige a capacidade de realizar inferências, assim como de conhecimento, por parte dos estudantes, dos gêneros tratados e de formas de retextualizá-los. Também é positiva a constatação de que o horizonte problemático e o horizonte indevido foram os menos recorrentes. De fato, no que diz respeito ao horizonte indevido, que consiste em uma interpretação errônea, desautorizada pelo texto base, este foi identificado apenas duas vezes. Além disso, o horizonte 
problemático, no qual se verifica a inserção de muitos elementos de conhecimento pessoal, o que favorece uma compreensão inadequada, foi identificado em uma única ocasião.

Tendo em vista o exposto, é possível concluir que, em sua grande maioria, a elaboração dos slides componentes da EO ocorreu sem prejuízos ao propósito comunicativo estabelecido pelos autores do AOP, sugerindo a compreensão desse último por parte dos graduandos do grupo em questão. Dessa forma, o presente artigo respalda ações desencadeadas no ensino superior de química por professores que desejem diversificar suas aulas a partir do uso de AOP, tendo em vista o desenvolvimento de habilidades valiosas para os graduandos, desde a iniciação científica (MASSI; QUEIROZ, 2010) até o desempenho futuro de tarefas como profissionais da área.

Cabe ainda notar que a construção de SD baseadas na leitura de AOP é favorecida pelo acesso a artigos dessa natureza, muitos deles disponíveis on-line e de forma gratuita nas universidades brasileiras. Ademais. no caso da pesquisa aqui relatada, a SD foi aplicada no segundo semestre do Curso de Bacharelado em Química, evidenciando a pertinência de tal leitura desde o início da graduação e corroborando o estudo desenvolvido por Hubbard e Dunbar (2017), que indicam diferentes níveis de dificuldade na compreensão dos mesmos, de acordo com o estágio do sujeito leitor na carreira acadêmica.

Por fim, é importante chamar atenção para o fato de poucos trabalhos reportados na literatura lidarem com a questão do uso de AOP pautados em referenciais teóricos para subsidiar a análise dos resultados obtidos a partir da sua aplicação em ambientes de ensino. Portanto, a adoção de referenciais teóricos, baseados nas ideias de Marcuschi $(2008,2010)$, aqui realizada, se constitui em uma ação valiosa que pode vir a contribuir com elementos importantes para o incremento de SD voltadas ao ensino de química no nível superior. 
AGRADECIMENTOS

À Fundação de Amparo à Pesquisa do Estado de São Paulo (FAPESP) pelo apoio financeiro (Processo 2018/23819-9). O presente trabalho foi realizado com apoio da Coordenação de Aperfeiçoamento de Pessoal de Nível Superior - Brasil (CAPES) Código de Financiamento 001.

\section{REFERÊNCIAS}

MINISTÉRIO DA EDUCAÇÃO; Conselho Nacional de Educação. Parecer CNE/CES Nº 1.303/2001 - Diretrizes Curriculares Nacionais para os Cursos de Química. Brasília (Brasil): Diário oficial da união; 2001.

BAKHTIN M. Os gêneros do discurso. Estética da criação verbal. São Paulo: Martins Fontes; 1979.

CARNEIRO MHS. As imagens no livro didático. In: $1^{\circ}$ Encontro Nacional de Pesquisa em Ensino de Ciências. 1997; Águas de Lindóia, Brasil. p. 366-373

CUNHA NB, SANTOS AAA. Relação entre a compreensão da leitura e a produção escrita em universitários. Psicologia: Reflexão e Crítica. 2006,19(2):237-245.

DASCAL, MA. A relevância do mal-entendido. Cadernos de Estudos Linguísticos. 1986;(11):199-217.

DELL'ISOLA RLP. Retextualização de gêneros escritos. Rio de Janeiro: Lucerna; 2007.

DOLZ J, SCHNEUWLY B, PIETRO JF, ZAHND G. A exposição oral. In: SCHNEUWLY, B.; DOLZ, J. Gêneros orais e escritos na escola. Campinas: Mercado de Letras, 2004. p. 215-246.

FRANCISCO JÚNIOR WE. Estratégias de leitura e educação química: que relações? Química Nova na Escola. 2010; 329(4): 220-226.

HUBBARD, KE, DUNBAR, SD. Perceptions of scientific research literature and strategies for reading papers depend on academic career stage. PLoS ONE. 2017;(12):1-16.

JOHNSTONE AH. Teaching of chemistry: logical or psychological? Chemistry Education: Research and Practice. 2000, 1(1):9-15.

KLEIMAN A. Texto e leitor: aspectos cognitivos da leitura. 11. ed. Campinas: Pontes; 2008. 
MARCUSCHI LA. Da fala para a escrita: atividades de retextualização. 10 ed. São Paulo: Cortez; 2010.

MARCUSCHI LA. Produção textual, análise de gêneros e compreensão. São Paulo: Parábola Editorial; 2008.

MASSI LS, SANTOS GR, FERREIRA, JQ, QUEIROZ SL. Artigo científico como recurso didático no ensino superior de química. Química Nova. 2010;32(2):503-510.

MASSI LS, QUEIROZ SL. Iniciação científica no ensino superior: funcionamento e contribuições. Campinas: Editora Átomo; 2010.

OAKHILL JV, CAIN K. Children's comprehension problems in oral and written language: a cognitive perspective. New York: Guilford; 2007.

OLIVEIRA JP, ANTUNES PWP, PINOTTI LM, CASSANI STA. Caracterização físico-química de resíduos oleosos do saneamento e dos óleos e graxas extraídos visando a conversão em biocombustíveis. Química Nova. 2014;37(4):597-602.

OLIVEIRA, JRS, QUEIROZ SL. A retórica da linguagem científica: das bases teóricas à elaboração de material didático para o ensino superior de química. Química Nova. 2012;35(4):851-857.

OLIVEIRA, JRS, QUEIROZ SL. Comunicação e linguagem científica: guia para estudantes de química. 2 ed. Campinas: Editora Átomo; 2017.

OLIVEIRA KL. Considerações acerca da compreensão em leitura no ensino superior. Psicologia: Ciência e Profissão. 2011;31(4):690-701.

QUEIROZ SL.; CABRAL PFO, SILVA EMS. Retextualização de artigos originais de pesquise por graduandos em química. Enseñanza de las Ciencias. 2017; (volume extra):4647-4652.

SÁ LP, FRANCISCO CA, QUEIROZ SL. Estudos de caso em química. Química Nova. 2007;30(3):731-739.

SÁ LP, QUEIROZ SL. Promovendo a argumentação no ensino superior de química. Química Nova. 2007;30(8):2035- 2042.

SANTOS, AMT. A retextualização na construção do discurso jurídico acadêmico [dissertation]. Recife: Universidade Católica de Pernambuco/UCP; 2006. 118 p.

SANTOS GR, QUEIROZ SL Leitura e interpretação de artigos científicos por alunos de graduação em química. Ciência \& Educação. 2007;13(2):193-209.

SANTOS, GR, SÁ LP, QUEIROZ SL. Uso de artigos científicos em uma disciplina de físico-química. Química Nova. 2006;29(5):1121-1128. 
SILVA AVL. Operações de retextualização no gênero exposição oral acadêmica. Revista Memento. 2011;2(2):70-89.

SPINILLO AG, MAHON ER. Compreensão de texto em crianças: comparações entre diferentes classes de inferência a partir de uma metodologia on-line. Psicologia: Reflexão e Crítica. 2007;20(3):463-471.

TEIXEIRA JÚNIOR JG, SILVA RMG. Perfil de leitores em um curso de Licenciatura em Química. Química Nova. 2007;30(5):1365-1368.

VAN DIJK TA, KINTSCH W. Strategies of discourse comprehension. New York: Academic Press; 1983. 